\title{
When Does Human Longevity Start?: Demarcation of the Boundaries for Human Longevity
}

\author{
NATALIA S. GAVRILOVA and LEONID A. GAVRILOV
}

\begin{abstract}
The scientific debates on the future of human life span and its possible biological limits revealed a great need for direct identification of longevity boundaries, if they really exist. The key question posed in this study is as follows: how can we possibly determine the age when human longevity starts? To address this problem, we studied the familial transmission of human life span from parents to daughters, since daughters did not have a high incidence of violent causes of death due to military service and are particularly responsive to parental life span. We found that the familial transmission of human life span from mother to daughter is essentially nonlinear with virtually no daughter-mother life span resemblance for shorterlived mothers (died before age 85 ) and very high familial resemblance (additive heritability) for longer-lived mothers. This indicates that maternal age of 85 years could be considered as a demarcation point (lower boundary) for female longevity. Women who live above this age are fundamentally (presumably genetically) different from other women in the sense that their daughters live significantly longer. Thus, the age of 85 years could be considered as a threshold age when women mortality becomes much more selective. A similar study of familial transmission of human life span from father to daughter revealed a demarcation point at 75 years, suggesting that this age might represent a lower boundary for male longevity. These results are also consistent with predictions of the evolutionary theory of aging and mutation accumulation theory in particular, namely that the additive genetic variance for human life span should increase with parental longevity. In other words, human mortality should become more selective at advanced ages, and this prediction is confirmed in the present study.
\end{abstract}

\section{INTRODUCTION}

$\mathbf{T}$ HE SCIENTIFIC DEBATES on the future of human life span and its possible biological limits ${ }^{1,2}$ revealed a great need for direct identification of longevity boundaries, if they really exist. $^{3,4}$ The key question posed in this study is as follows: how can we possibly determine the age when human longevity starts? To address this problem, we studied the familial transmission of human life span from parents to daughters, since daughters did not have a high incidence of violent causes of death due to military service and are known to be particularly responsive to parental life span. ${ }^{5}$ If human life span is inherited just as any other polygenic quantitative trait, then the monotonic linear dependence between offspring life span and parental life span is expected. ${ }^{6,7}$ In this case, no evidence for any boundaries of human longevity could be detected. On the other hand, if a special age corresponding to longevity

Center on Aging, NORC/University of Chicago, Chicago, Illinois. 
boundary does really exist, this could be detected as a breaking point in the offspring-parent life span dependence. In this study, we found evidence for breaking points at about 85 years for females (mothers) and at about 75 years for males (fathers) that allowed us to identify the lower boundaries for human longevity in males and females.

\section{DATA AND METHODS}

\section{Main data source}

In this study, we collected, computerized, and analyzed detailed genealogical records on life span of 5,779 adult daughters (30+ years) and their parents, using particularly reliable and complete data on European royal and noble families for extinct birth cohorts (born 1800-1880). The main advantage of these data is their high accuracy, reliability, and completeness. Another advantage of this kind of data is the relative homogeneity of this Caucasian population regarding social class and educational background. Since this privileged social group lived in favorable conditions, one could expect less influence of adverse social factors (poverty, for example) on life span and hence lower bias caused by these factors. This kind of data allows us to minimize the social heterogeneity of the population under study. Thus, although the sample analyzed in this study does not represent the whole human population (as laboratory animals do not represent species in the wild), it is one of the best possible samples to test biogerontological hypotheses since the effects of population heterogeneity are minimized with regard to social status.

The database on European royal and noble families (a family-linked database) was developed as a result of 5 years of our continued effort, and the earlier intermediate versions of this database were used in our previous studies. ${ }^{5,8-15}$ To develop this database, we have chosen one of the best professional sources of genealogical data available-the famous German edition of the "Genealogisches Handbuch des Adels" (Genealogical Yearbook of Nobility). This edition is known world wide as the "Gotha Almanac" - "Old Gotha" published in Gotha in 1763-1944 and "New Gotha"16 published in
Marburg since 1951 (for more details, see elsewhere ${ }^{17}$ ). Data from the Gotha Almanach were widely used in early biodemographic studies of fertility (for references, see elsewhere ${ }^{18}$ ) and proved to be useful now in the studies of human longevity. $5,8,11,12$

Each volume of the New Gotha Almanach contains about 2,000 genealogical records dating back to the 14th-16th centuries (to the founder of a particular noble genus). More than 100 volumes of this edition are already published, so more than 200,000 genealogical records with well-documented genealogical data are available from this data source. The high quality of information published in this edition is ensured by the fact that the primary information is drawn from the German Noble Archive (Deutsches Adelsarchiv). The Director of the German Noble Archive (Archivdirektor) is also the Editor of the New Gotha Almanach. Our own experience based on cross-checking the data, has demonstrated that the number of mistakes (mostly misprints) is very low in the "New Gotha Almanac" (less than one per 1,000 records), so this source of data is very accurate compared to other published genealogies.

The information on noble families in the New Gotha Almanac is recorded in a regular manner. The description of each particular noble genus starts with information on two to three generations of founders of male sex only. Then three to four of the most recent generations are described in more detail, including information on individuals (e.g., first and last names; event data, i.e., birth, death, marriage dates and places; descriptive data, i.e., noble degrees, occupation if available, information on death circumstances if available), information on parents (e.g., first and last names; event data, i.e., birth and death dates and places), information on spouses (e.g., first and last names; birth and death dates and places; first and last names of parents), and information on children (detailed as for each individual).

The process of data computerization was started from the most recent volumes of the New Gotha Almanac (published in 1990-1994) and reached the volumes published 10 years earlier. The database on European aristocratic families comprises more than 20,000 personal records and is growing further. 
Supplementary data sources

Some other supplementary sources of data were used in the development of database. These data sources included two computerized data files on European royalty and British peerage (computerized database "Royal92" distributed on the Internet by Brian C. Tompsett at the University of Hull, U.K., and database on British Peerage distributed on CD by S\&N Genealogy Supplies), as well as over 100 genealogical publications on Russian nobility listed elsewhere. ${ }^{19}$ These data were used as a supplement to the main data source since their quality was not as high compared to the Gotha Almanac. Although data on European royalty were recorded in computerized data sources ("Royal92", British Peerage CD) with sufficient completeness, data on lower rank nobility (landed gentry) were less complete and accurate. The same was true for the data on Russian nobility. All supplementary data were matched with the Gotha Almanac data, in order to cross-check the overlapping pieces of information. This cross-checking procedure allowed us to increase the completeness of the database by complementation of information taken from different sources.

\section{The structure of genealogical database}

The database approach used in this study is similar to the approach used for existing family-linked databases, such as the Utah Population Database, ${ }^{20}$ Laredo Epidemiological Project $^{21}$ or other historical databases. ${ }^{22}$

Each record in the database represents an individual's event data (birth and death dates and places) and individual's descriptive information, that is, identification number, sex, first and last names, nobility rank, occupation, birth order, cause of death (violent/nonviolent), ethnicity, marital status, data source code number, and data source year of publication. Individual information is supplemented by data for parents (identification numbers, first and last names, birth, death and marriage dates, cause of death) and spouses. Thus, the database that is used in this study is organized in the form of triplets (referred to as the "ego" and two parents). This structure of records is widely used in human genetics and is adequate for studies of parent-child relationships. Similar database structure was used in the recent study of kinship networks. ${ }^{23}$

\section{Data quality control}

Data quality control was an important part of our study designed to develop high quality family-linked database and to use it in research of familial longevity.

The genealogical data sources were checked for the following: (1) completeness - in reporting birth and death dates, which is crucial for calculating individual life span, the variable of particular interest in our study; (2) accuracywhether the percentage of mistakes and inconsistencies between reported dates (such as, for example, birth by the dead mother) is low enough to be acceptable; and (3) representativeness-whether the characteristics of investigated data sets (distribution by age, sex, marital status, age at death, etc.) are close enough to demographic characteristics of populations in similar geographic areas, historical periods, and social groups. In our study, we referred to the well-known publication by Thomas Hollingsworth ${ }^{24}$ on British peerage as a standard for European aristocracy, to check for data representativeness.

The completeness in birth and death dates reporting in the New Gotha Almanac was very high: dates of all vital events were reported for nearly $95 \%$ of all persons. Such high completeness is not common for many other genealogical data sources. For example, for British Peerage data published in Burke almanac in most cases there are no birth dates for women, which makes the calculation of their life span impossible. In fact, this problem (with British aristocratic women) was first noticed a century ago by Karl Pearson. ${ }^{25,26}$ He used the British Peerage data to study the longevity inheritance and had to exclude women from his consideration for the following reason: "The limitation to the male line was enforced upon us partly by the practice of tracing pedigrees only through the male line, partly by the habitual reticence as to the age of women, even at death, observed by the compilers of peerages and family histories" .26

The accuracy of data published in the New 
Gotha Almanac is also very high: the frequency of inconsistent records is less than one per 1,000 records, while for many other genealogical data sources, it falls within one per 300-400 records.

As for representativeness, the comparison of our data with Hollingsworth's analysis of British peerage ${ }^{24}$ revealed good agreement between his findings and our data on mortality patterns, including significant male/female gap in life expectancy (7-10 years of female advantage in life span).

The genealogies for the members of European aristocratic families presented in the "Gotha Almanac" are of descending type, tracing almost all the descendants of relatively few founders. This is an important advantage of this data source over other genealogies that are often of ascending type (pedigrees). It is known in historical demography that the ascending genealogies are biased, overrepresenting more fertile and longer-lived persons who succeed to become ancestors, and for this reason such genealogies should be treated with particular caution. ${ }^{27,28}$

Thus, the genealogical data published in the Gotha Almanac are characterized by high quality and accuracy. We have, however, encountered two problems regarding the data completeness, which are discussed below, along with proposed solutions.

1. Censored, truncated observations and missing death dates. Our study revealed that the percentage of cases with unreported death dates is rather small in our main data sources (Gotha Almanac) and is caused mainly by the right censoring of long-lived persons who were still alive by the date of data collection and publication. The percentage of non-reported death dates varies from $0 \%$ to $7 \%$ in extinct birth cohorts (1800-1880), while it is higher in later birth cohorts (1880-1899) - 23\% for women and $8 \%$ for men, since some individuals were still alive by the date of data collection and volume publication. Note that women, who live longer, have a higher proportion of right-censored observations. The high proportion of censored observations in genealogies is not desirable, since the exact dates of censoring are often unknown. This uncertainty creates problems for data analysis, so the researchers working with ge- nealogies prefer to use noncensored, extinct birth cohorts in their studies. ${ }^{29-31}$ We also used extinct (noncensored) birth cohorts in our study. For this purpose, only those birth cohorts were used in the study that were born at least 100 years before the year of data publication (to be sure that the birth cohort under study is almost extinct).

2. Underreporting of women and children. In many genealogical books and databases, nonmarried women as well as children who died in infancy are often missed or reported with less completeness. Since genealogical records are focused on family names, which are transmitted by males only, women could be lost in genealogies when they marry and change their family names. ${ }^{32}$ Also, in many cases, data for women do not contain information on their birth and death dates resulting in biased sex ratio in the sample with complete dates. We have also encountered this problem in our studies although for somewhat different reason. Our analysis revealed that the main cause of the sex bias in the New Gotha Almanac is related to the manner of data representation: more recent generations are presented completely, while earlier generations are limited mainly to the male ancestors (in order to avoid repetitive publication of complete genealogies already presented in previous volumes). That is why the sex ratio among early birth cohorts (1800-1860) is biased in favor of males, while for more recent birth cohorts (1880-1899) it is within the normal range. Since in our study the most recent volumes of the New Gotha Almanac (published after 1980) were computerized and analyzed (in order to avoid censoring), the proportion of males in extinct birth cohorts (early generations) was substantially higher than expected. The ideal way to overcome this sex bias problem is to ensure complete coverage of all aristocratic genuses and families ever published in the Gotha Almanac (although it may take a long time to computerize all 100 volumes). The alternative way is to computerize complete data on early birth cohorts published in old volumes. In this case, however, the data will be heavily right-censored since many persons would not have death date (be still alive) by the date of publi- 
cation. We plan to continue computerization of these genealogies using combination of both strategies and data cross-checking. This will allow us to eliminate eventually the sex bias and potential problems associated with it. Sex bias is an important issue in fertility studies since the fertility levels are understated when daughters are underreported, ${ }^{33}$ but in the case of longevity studies this issue is less important. ${ }^{34}$ According to Wyshak, "in the ... analysis of longevity, there is no reason to believe that women about whom information is not recorded differ from those whose records have been traced." 34

The underreporting of children who died in infancy may be also a serious problem, especially for studies that include fertility analysis. Fortunately, in the Gotha Almanac the families that belong to the higher nobility rank (kings, princes, earls) are described with remarkable completeness. In particular, all ever born children are recorded, including those who died the same day when they were born. Another indicator of data completeness is the normal sex ratio at birth (101-108) observed among these families (based on analysis of our sample). In our database, over 90 aristocratic genuses belonged to the upper nobility were recorded completely, although data for lower rank nobility were not yet completed. Underreporting of children is not a problem for this particular study that is focused on adult life span for those who survived by age 30 years.

\section{Analytical methods}

Since the data used in this study are characterized by remarkable accuracy and completeness, it was possible to apply simple and straightforward methods of data analysis without making heavy assumptions. In particular, since the length of life is known for every person (there were no right-censored observations), it was possible to analyze the duration of life directly as a dependent, outcome variable in linear regression model. There was no need to apply the Cox proportional hazard model and to make a strong assumption about multiplicative effects of covariates on hazard rate. Instead, daughters' life span was considered as a linear function of parental life span, and this assumption of linear dependence between parental and offspring traits is well justified both in the theory and practice of quantitative genetics. ${ }^{6,7}$ Two additional features were introduced in this simple linear regression model:

1. A piece-wise linear regression model was applied to test whether the regression slope coefficients of linear regression of daughters' life span on parental life span are different, if calculated for different ranges of parental life span.

2. To control for secular changes in life expectancy, an additional internal control variable was included in the analysis as an independent predictor of daughters' life span. Specifically, the mean life span of adult daughters $\left(30^{+}\right.$years $)$was calculated for each calendar year of birth (81 birth cohorts for years 1800-1880). This variable was then included into linear regression model as a predictor variable for individual life span of each daughter matched for the same year of birth. This method was already applied earlier in a similar study ${ }^{5}$ to regress out the secular changes in life span.

Data for plots (Figs. 1 and 2) were calculated in the following way. First, the data on individual life span were centered around the mean adult life span in the same birth cohorts in order to control for secular changes in life span. In other words, the residuals were calculated as the differences between individual life span and the cohort mean life span for the same calendar year of birth. These residuals (deviations from population mean) were then plotted against parental life span to see whether the average values of these residuals (calculated for each particular 1-year group of parental life span) are close to zero (expected if parental life span is of no importance), or whether they are increasing with parental life span (expected in the case of life span inheritance). The dependence of averaged residuals on parental life span was generated and then smoothed by 5year moving average in order to decrease the statistical noise and to reveal the pattern of this dependence. These plots were used to detect visually the possible breaking points in linear 
dependence for subsequent piece-wise regression analysis.

\section{RESULTS AND DISCUSSION}

Figure 1 depicts the dependence between daughters' life span and maternal life span. This dependence looks like consisting of two pieces. Daughters born to shorter-lived mothers (died before 85 years) seem to demonstrate very weak resemblance with maternal life span. It does not really matter for daughters' life span whether their mothers lived 40 years only, or as long as 80 years-the corresponding increase in daughters' life span is below 2 years for 40 years of additional maternal life span.

On the other hand, daughters born to longerlived mothers (died after 85 years) demonstrate remarkably steep increase of their life span with maternal life span (Fig. 1).

These graphical observations are confirmed by statistical analysis presented at Table 1.
The familial transmission of human life span from mother to daughter is essentially nonlinear (consisting of two different lines) with virtually no familial resemblance for shorter-lived mothers (died before 85 years)-the slope coefficient $(b)$ of linear regression for daughters' life span on maternal life span is insignificant $(b=0.002 \pm 0.020, n=4,983$ cases, $p=0.941)$. However, for longer-lived mothers (died after 85 years), a very high familial resemblance (additive heritability) is observed: $b=0.412 \pm$ $0.204(n=619$, significant at $p<0.05)$. In other words, for each additional 10 years of life span of longer-lived mothers, daughters gain additional $4.12 \pm 2.04$ years of life span on average. In quantitative genetics, the narrow-sense heritability of any trait is estimated as the doubled regression slope coefficient for offspring-onparent dependence. ${ }^{6,7}$ Thus, after maternal age of 85 years the narrow-sense heritability of human life span increases from virtually zero to $82.4 \pm 40.8 \%$ for mother-to-daughter familial transmission of life span. This indicates that maternal age of 85 years could be considered

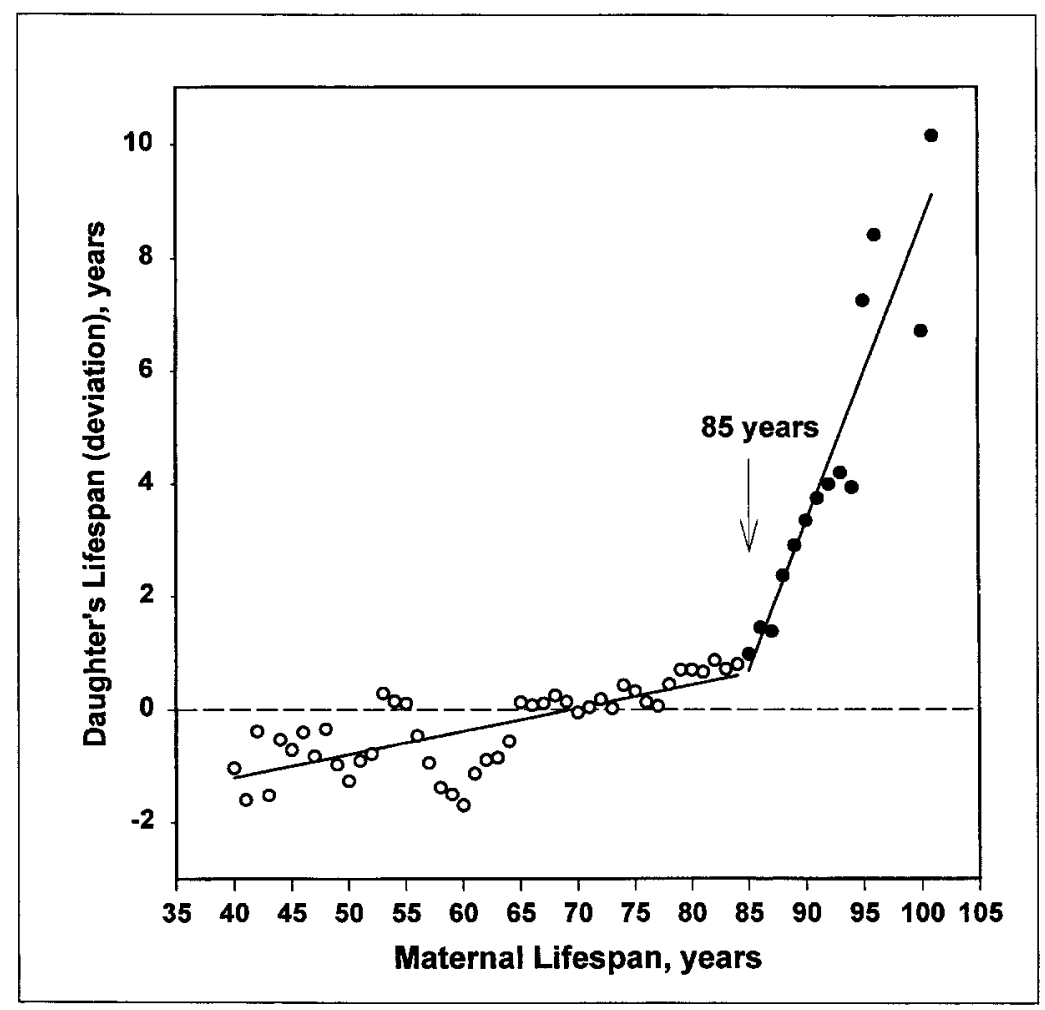

FIG. 1. Daughter's life span (deviation from the cohort mean) as a function of maternal life span. Based on the data for 5,779 daughters from European royal and noble families born in 1800-1880 and survived by age 30. Data are smoothed by 5 -year moving average. 
Table 1. Heritability of Human life Span (Regression Slope of Daughter's Life Span on Maternal Life Span) as a Function of Maternal Life Span Rangea

\begin{tabular}{lcc}
\hline Parameters of the linear regression model & $\begin{array}{c}\text { Daughters of shorter-lived } \\
\text { mothers (30-85 years) }\end{array}$ & $\begin{array}{c}\text { Daughters of longer-lived } \\
\text { mothers (85-95 years) }\end{array}$ \\
\hline $\begin{array}{l}\text { Regression slope (daughters' life span on } \\
\text { maternal lifespan) }\end{array}$ & 0.002 & 0.412 \\
Standard error for regression slope & & \\
$t$ ratio & 0.020 & 0.204 \\
Significance $(p$ value) & 0.07 & 2.02 \\
Number of cases & 0.941 (insignificant) \\
Range for maternal life span, years & 4,983 & 0.044 (significant) \\
\hline
\end{tabular}

${ }^{a}$ The data are for extinct birth cohorts, born 1800-1880, European royal and noble families.

as a demarcation point for women's longevity (its lower boundary). Women who live above this age are fundamentally (presumably genetically) different from other women in the sense that their daughters live significantly longer. Thus, the age of 85 years could be considered as a threshold age when female mortality becomes much more selective, and this age threshold in death selectivity should be taken into account in biogerontological studies of hu- man longevity as well as in forecasting human life expectancy for women.

Figure 2 demonstrates the dependence between daughters' life span and paternal life span. This dependence also looks like consisting of two lines, but the breaking point between these two lines is observed at earlier parental age-about 75 years. Daughters born to shorter-lived fathers (died before 75 years) do not inherit paternal life span. It does not mat-

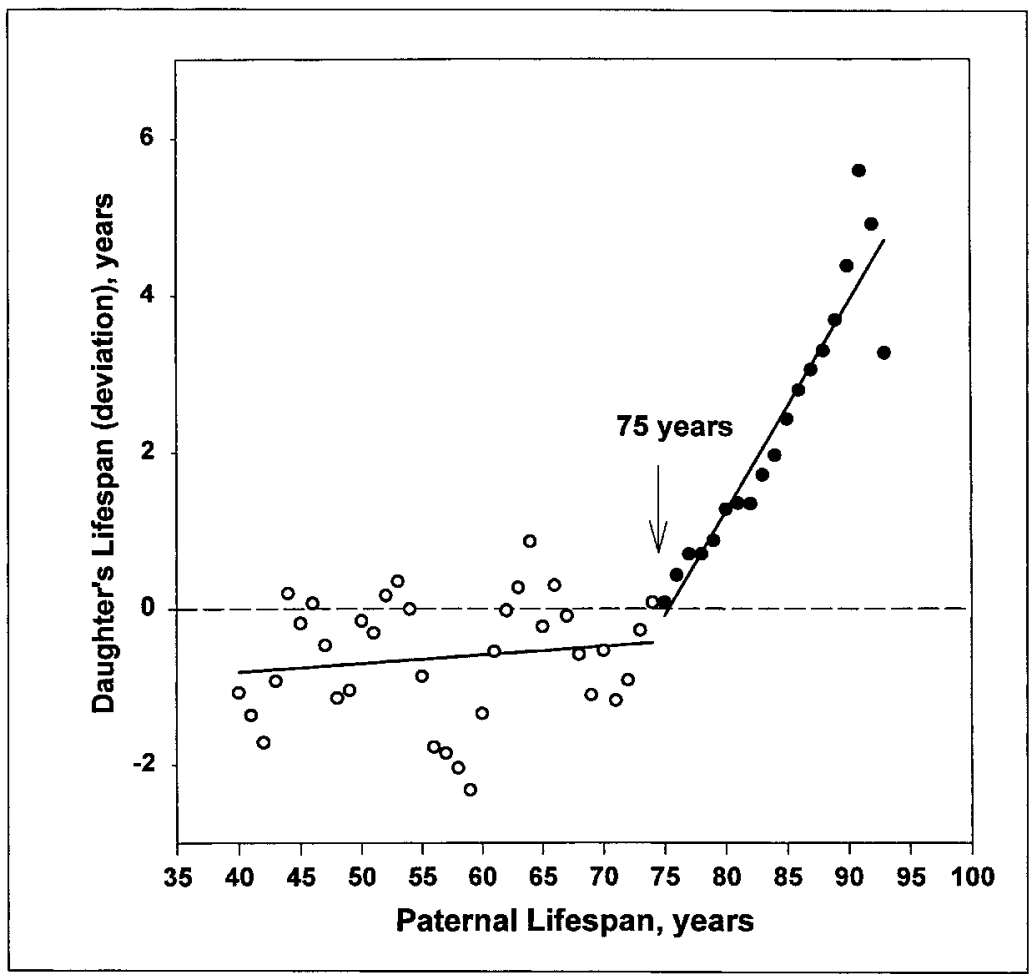

FIG. 2. Daughter's life span (deviation from the cohort mean) as a function of paternal life span. Based on the data for 5,779 daughters from European royal and noble families born in 1800-1880 and survived by age 30. Data are smoothed by 5 -year moving average. 
ter for daughters' life span whether their fathers lived 40 years only, or 70 years-the increase in daughters' life span is negligible despite increase in paternal life span by 30 years (Fig. 2).

On the contrary, daughters born to longerlived fathers (died after 75 years) demonstrate rather steep dependence of their life span on paternal life span (Fig. 2).

These graphical observations are confirmed by statistical analysis presented at Table 2 .

A study of familial transmission of human life span from father to daughter suggests a demarcation point at 75 years, indicating that this age may represent a lower boundary for male longevity. The familial transmission of human life span from father to daughter is also nonlinear (consisting of two different lines), with virtually no resemblance before paternal life span of 75 years (regression slope coefficient, $b=-0.007 \pm 0.034, n=4,011$ cases, $p=$ 0.829 , insignificant) and much higher additive heritability for longer-lived fathers $(b=$ $0.236 \pm 0.078, n=1,756$ cases, $p<0.01$ ). In other words, for each additional 10 years of life span of longer-lived fathers (died after 75 years), daughters gain additional $2.36 \pm 0.78$ years of life span on average. Thus, after paternal age of 75 years, the narrow-sense heritability of human life span (doubled regression slope coefficient) increases from virtually zero to $47.2 \pm 15.6 \%$ for father-to-daughter familial transmission of life span.

The obtained results are consistent with the predictions of the evolutionary theory of aging and mutation accumulation theory in particular, namely that the additive genetic variance for human life span should increase with parental longevity. ${ }^{35}$ In other words, human mortality should become more selective at advanced ages, ${ }^{5}$ observed in this study.

The results obtained in this study also explain the existing longevity paradox: although the heritability estimates for life span were reported to be rather low, 3,34,37-39 it is well known that cases of extreme longevity have a strong familial association. ${ }^{40-43}$ This paradox is explained by our finding that heritability of human life span is low only when studied in the whole range of parental life span (because most of the parents did not live long lives in historical populations studied so far), but is quite high when estimated specifically for longerlived parents. The results of this pilot exploratory study justifies the need for further full-scale research project on trajectories of parent-offspring transmission of human longevity. Further studies on larger samples with additional consideration of many other explanatory and confounding variables (such as parental ages at person's birth, etc.) are planned and may shed more light on the mechanisms of life span inheritance and the boundaries for human longevity.

\section{ACKNOWLEDGMENTS}

We are most grateful to Victoria G. Semyonova and Galina N. Evdokushkina for computerization of the genealogical data for this study. We would also like to acknowledge support from the grants of the National Institute on Aging. The earlier version of this study was

Table 2. Heritability of Human Life Span (Regression Slope of Daughter's Life Span on Paternal Life Span) as a Function of Paternal Life Span Range ${ }^{a}$

\begin{tabular}{lcc}
\hline Parameters of the linear regression model & $\begin{array}{c}\text { Daughters of shorter-lived } \\
\text { fathers (30-75 years) }\end{array}$ & $\begin{array}{c}\text { Daughters of longer-lived } \\
\text { fathers (75-95 years) }\end{array}$ \\
\hline $\begin{array}{l}\text { Regression slope (daughters' life span on } \\
\text { paternal life span) }\end{array}$ & -0.007 & 0.236 \\
Standard error for regression slope & 0.034 & 0.078 \\
$t$ ratio & -0.22 & 3.04 \\
Significance $(p$ value) & 0.829 (insignificant) & 4,011 \\
Number of cases & $30-75$ & 0.002 (significant) \\
Range for paternal life span, years & 7,756 \\
\hline
\end{tabular}

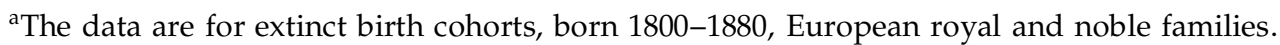


presented at the Annual Meeting of the Population Association of America (Los Angeles, 2000), and we would like to thank the participants of this meeting for useful suggestions regarding our study.

\section{REFERENCES}

1. Olshansky SJ, Carnes BA, Cassel C. In search of Methuselah: estimating the upper limits to human longevity. Science 1990;250:634-640.

2. Olshansky SJ, Carnes BA, Désesquelles A. Prospects for human longevity. Science 2001;291:1491-1492.

3. Gavrilov LA, Gavrilova NS. The Biology of Life Span: A Quantitative Approach. New York: Harwood Academic Publisher, 1991.

4. Gavrilov LA, Gavrilova NS. The future of long life. Science 1998;281:1611-1612.

5. Gavrilova NS, Gavrilov LA, Evdokushkina GN, Semyonova VG, Gavrilova AL, Evdokushkina NN, Kushnareva YuE, Kroutko VN, Andreyev A. Yu. Evolution, mutations and human longevity: European royal and noble families. Hum Biol 1998;70:799-804.

6. Falconer DS, Mackay TFC. Introduction to Quantitative Genetics. London: Longman, 1996.

7. Lynch M, Walsh B. Genetics and Analysis of Quantitative Traits. Sunderland, MA: Sinauer, 1998.

8. Gavrilov LA, Gavrilova NS. Parental age at conception and offspring longevity. Rev Clin Gerontol 1997;7:5-12.

9. Gavrilov LA, Gavrilova NS. When should fatherhood stop? Science 1997;277:17-18.

10. Gavrilov LA, Gavrilova NS. Season of birth and human longevity. J Anti-Aging Med 1999;2:365-366.

11. Gavrilov LA, Gavrilova NS. Human longevity and parental age at conception. In: Robine J-M, Kirkwood TBL, Allard M, eds. Sex and Longevity: Sexuality, Gender, Reproduction, Parenthood. Berlin: Springer-Verlag, 2000:7-31.

12. Gavrilov LA, Gavrilova NS. Biodemographic study of familial determinants of human longevity. Population, English Selection 2001;13:197-222.

13. Gavrilov LA, Gavrilova NS, Semyonova VG, Evdokushkina GN, Gavrilova AL, Evdokushkina NN, Lapshin EV. Human longevity genes are located in X-chromosome [Abstract no. 020.0027]. In: Knook DL, Dittman-Kohli F, Duursma SA, et al. eds. Ageing in a Changing Europe. Utrecht: Netherlands Institute of Gerontology, 1995.

14. Gavrilov LA, Gavrilova NS, Kroutko VN, Evdokushkina GN, Semyonova VG, Gavrilova AL, Lapshin EV, Evdokushkina NN, Kushnareva YuE. Mutation load and human longevity. Mutat Res 1997;377:61-62.

15. Gavrilova NS, Semyonova VG, Gavrilov LA, Evdokushkina GN, Gavrilova AL, Lapshin EV, Evdokushkina NN. Biomedical basis of sex differen- tial in human life span [Abstract no. 020.0028]. In: Knook DL, Dittman-Kohli F, Duursma SA, et al., eds. Ageing in a Changing Europe. Utrecht: Netherlands Institute of Gerontology, 1995.

16. Van Hueck W, ed. Genealogisches Handbuch des Adels. Limburg an der Lahn: C.A. Starke Verlag, 1951-1994.

17. Gavrilova NS, Gavrilov LA. Data resources for biodemographic studies on familial clustering of human longevity. Demographic Res 1999;1:1-48. Available: http://www.demographic-research.org/volumes/ Vol1/4/

18. Hollingsworth TH. Historical Demography. Ithaca, NY: Cornell University Press, 1969.

19. Gavrilov LA, Gavrilova NS, Evdokushkina GN, Semyonova VG, Gavrilova AL, Lapshin EV, Evdokushkina NN, Kushnareva YuE. Determinants of human longevity: parental age at reproduction and offspring longevity. Longevity Rep 1996;10:7-15.

20. Skolnick M, Bean LL, Dintelman SM, Mineau G. A computerized family history data base system. Sociol Soc Res 1979;63:506-523.

21. Buchanan AV, Weiss KM, Schwartz RJ, MacNaughton NL, McCartan MA, Bates SS. Reconstruction of genealogies from vital records: the Laredo Epidemiology Project. Comput Biomed Res 1984;17: 326-351.

22. Gutmann M, Fliess KH, Holmes AE, Fairchild AL, Teas WA. Keeping track of our treasures: managing historical data with relational database software. Historical Methods 1989;22:128-143.

23. Post W, Van Poppel F, Van Imhoff E, Kruse E. Reconstructing the extended kin-network in the Netherlands with genealogical data: methods, problems, and results. Pop Studies 1997;51:263-278.

24. Hollingsworth TH. The demography of the British Peerage. Popul Studies 1962;18(suppl):3-107.

25. Beeton M, Pearson K. Data for the problem of evolution in man. II: A first study of the inheritance of longevity and the selective death rate in man. Proc $R$ Soc Lond 1899;65:290-305.

26. Beeton M, Pearson K. On the inheritance of the duration of life and the intensity of natural selection in man. Biometrika 1901;1:50-89.

27. Jetté R, Charbonneau H. Généalogies déscendantes et analyse démographique. Ann Demogr Historique 1984;45-54.

28. Fogel RW. New sources and new techniques for the study of secular trends in nutritional status, health, mortality, and the process of aging. Historical Methods 1993;26:5-43.

29. Mayer PJ. Inheritance of longevity evinces no secular trend among members of six New England families born 1650-1874. Am J Hum Biol 1991;3:49-58.

30. Pope CL. Adult mortality in America before 1900. A view from family histories. In: Goldin $\mathrm{C}$, Rockoff $\mathrm{H}$, eds. Strategic Factors in Nineteenth Century American Economic History. A Volume to Honor Robert W. Fogel. Chicago: Univiversity of Chicago Press, 1992:267296.

31. Kasakoff AB, Adams JW. The effect of migration on 
ages at vital events: a critique of family reconstitution in historical demography. Eur J Popul 1995;11:199-242

32. Hollingsworth TH. Genealogy and historical demography. Ann Demogr Historique 1976;167-170.

33. Gavrilov LA, Gavrilova NS. Is there a reproductive cost for human longevity? J Anti-Aging Med 1999;2: 121-123.

34. Wyshak G. Fertility and longevity of twins, sibs, and parents of twins. Soc Biol 1978;25:315-330.

35. Hughes KA, Charlesworth B. A genetic analysis of senescence in Drosophila. Nature 1994;367:64-66.

36. Murphy EA. Genetics of longevity in man. In: Schneider E, ed. The Genetics of Aging. New York, Plenum Press, 1978:261-301.

37. McGue M, Vaupel JW, Holm N, Harvald B. Longevity is moderately heritable in a sample of Danish twins born 1870-1880. J Gerontol 1993;48:B237-B244.

38. Finch CE, Tanzi RE. Genetics of aging. Science 1997;278:407-411.

39. Carnes BA, Olshansky SJ, Gavrilov LA, Gavrilova NS, Grahn D. Human longevity: nature vs. nurture-fact or fiction. Perspect Biol Med 1999;42: 422-441.
40. Pearl R. Studies on human longevity. IV. The inheritance of longevity. Preliminary report. Hum Biol 1931;3:245-269.

41. Pearl R, Dewitt R. Studies on human longevity. VI. The distribution and correlation of variation in the total immediate ancestral longevity of nonagenarians and centenarians, in relation to the inheritance factor in duration of life. Hum Biol 1934;6:98-222.

42. Pearl R, Pearl RDW. The Ancestry of the Long-Lived. Baltimore: The Johns Hopkins Press, 1934.

43. Perls T, Alpert L, Wager CG, Vijg J, Kruglyak L. Siblings of centenarians live longer. Lancet 1998;351:1560.

Address reprint requests to: Dr. Natalia S. Gavrilova

Center on Aging NORC/University of Chicago 1155 East 60th Street Chicago, IL 60637

E-mail: nsgavril@midway.uchicago.edu 